\title{
A COMPANHIA NEGRA DE REVISTAS NOS ECOS DO PROJETO CIVILIZATÓRIO BRASILEIRO AS ATUALIZAÇÕES DOS DISCURSOS SOBRE NAÇÃO E CIVILIZAÇÃO NA TRAJETÓRIA DA COMPANHIA
}

Daniele Lopes dos Santos (UNIRIO)

O artigo aborda a história da Companhia Negra de Revistas, relacionando-a ao contexto histórico da construção do Projeto Civilizatório Brasileiro, sob o foco do uso da mestiçagem como característica formadora do caráter nacional e suas implicações em diálogos transculturais.

TEATRO BRASILEIRO; RELAÇÕES RACIAIS; PROJETO CIVILIZATÓRIO; IDENTIDADE NACIONAL; TEATRO DE REVISTA.

SANTOS, Daniele Lopes dos. A Companhia Negra de Revistas nos ecos do Projeto Civilizatório Brasileiro: as atualizações dos discursos sobre nação e civilização na trajetória da Companhia. Textos escolhidos de cultura e arte populares, Rio de Janeiro, v.12, n.1, p. 103-118, mai. 2015. 


\section{THE COMPANHIA NEGRA DE REVISTAS UNDER THE BRAZILIAN CIVILIZATORY PROJECT}

UPDATING DISCOURSES ON NATION AND CIVILIZATION IN THE COMPANY'S TRAJECTORY

Daniele Lopes dos Santos (UNIRIO)

This article deals with the history of the Companhia Negra de Revistas, establishing a relation to the historical context of the construction of the "Brazilian Civilizatory Project", focusing on miscegenation as characteristic in the formation of the national character and its implications in transcultural dialogues.

BRAZILIAN THEATER; RACE RELATIONS; CIVILIZATORY PROJECT; NATIONAL IDENTITY; VAUDEVILLE SHOWS.

SANTOS, Daniele Lopes dos. A Companhia Negra de Revistas nos ecos do Projeto Civilizatório Brasileiro: as atualizações dos discursos sobre nação e civilização na trajetória da Companhia. Textos escolhidos de cultura e arte populares, Rio de Janeiro, v.12, n.1, p. 103-118, mai. 2015. 


\section{ATO I: BREVE HISTÓRICO DA PERSONAGEM E DO ATOR NEGRO NO TEATRO BRASILEIRO}

A história das manifestações teatrais no Brasil, presentes na bibliografia especializada que se propõe dar conta das práticas iniciais das artes cênicas no país, considera o teatro jesuítico, fortemente didático, a primeira forma de manifestação teatral aqui presente, "tendo surgido com a catequese das tribos indígenas feita pelos missionários da recém-fundada Companhia de Jesus" (PRADO, 2012, p.21).

Em finais do século XVIII, a arte teatral, já desvinculada de fins religiosos, ganha os primeiros espaços próprios com a construção de Casas de Ópera e Comédia. Como consequência, data da mesma época o surgimento dos primeiros grupos organizados profissionalmente e que ocupavam tais espaços. Nesse primeiro momento, as companhias teatrais contavam com elenco predominantemente negro ou mulato:

os brancos só raramente, em papéis de personagens estrangeiros (...) O próprio Tomás Antônio Gonzaga, bem antes, numa de suas Cartas chilenas, comentara sob a voz de Critilo: "Ordena-se também que nos teatros/Os três mais belos dramas se estropiem/Repetidos por bocas de mulatos." Essa predominância de negros e mulatos nos elencos teatrais da época se devia, provavelmente, ao preconceito generalizado contra a profissão de ator, julgada desprezível pelas camadas superiores. Apelava-se, então, para o negro ou mulato, escravo ou liberto, já por si de condição degradada, indiferentes, portanto, ao preconceito (MENDES, 1982, p. 3).

Com a vinda da família real portuguesa para o Brasil, em 1808, há uma série de melhorias em diversos níveis da vida fluminense, o artístico entre eles. Segundo Miriam Mendes (1982, p. 3),

Companhias estrangeiras de teatro declamado, de dança, de canto, tornaram-se frequentes nos teatros da época, quer durante a permanência de D. João VI, quer durante os anos do Primeiro Reinado. $O$ ator negro desaparece dos palcos fluminenses, pelo menos os que representavam papéis importantes.

A progressiva valorização da profissão de ator e o proporcional apagamento do negro como artista da cena ao longo do século, vêm acompanhados da emergência de uma dramaturgia "nacional" que, a partir de 1851, recoloca o negro em cena através da representação estereotípica de sua figura, frequentemente retratada como a do escravo fiel, elemento grotesco ou criminoso, facilmente observada por um exame mais profundo da criação dramatúrgica do século XIX, 
no Brasil. Assim, entende-se a "invisibilização" do elemento negro como um processo claramente político-ideológico formado por discursos que categorizam e aprisionam o elemento negro. De acordo com Leda Maria Martins (1995, p. 43),

Através dessas marcas constantes na dramatização da persona negra, a convencionalização teatral repete um discurso do saber que se propõe como verdade. E é como saber e como verdade que esse discurso faz circular o poder estruturante e modelador das relações raciais no Brasil, legitimando, no estatuto dos personagens, o estatuto mesmo das práticas de domínio social.

Nesse sentido, a cor da pele é determinante de um lugar social e como contramão desse mesmo processo, a condição social é determinante da cor:

A ideia de escravo estava intimamente ligada à ideia de negro, duas coisas que se confundiam aos olhos do senhor branco e dentro de um conceito que, embora sendo, aparentemente, apenas social, na verdade considerava as gradações da cor de pele do indivíduo como justificativa para mantê-lo dentro da categoria racial a que seus pais pelo menos pertenciam. Em outras palavras, sendo negros puros os primeiros escravos vindos para o Brasil, logo a sua cor começou a indicar também a condição social e, por extensão, num raciocínio simplista, bastava o indivíduo ser escravo para ser visto como negro, ainda que a cor de sua pele não fosse muito escura (...) O fato de ser negro e escravo, portanto, condições racial e social por si mesmas degradantes, colocava o indivíduo em situação de extrema inferioridade dentro de uma sociedade branca, na qual, certamente, não lhe seria fácil tornar-se um objeto estético, segundo os padrões convencionais (MENDES, 1982, p. 21).

Dessa forma, podemos entender que tanto o veto ao ator negro quanto a esteriotipia da representação do negro como personagem estão ligados a sua negritude tomada como elemento produtor de marcas semióticas.

Assim, a cor de um indivíduo nunca é simplesmente uma cor, mas um enunciado repleto de conotações e interpretações articuladas socialmente, com um valor de verdade que estabelece marcas de poder, definindo lugares, funções e falas (MARTINS, 1995, p. 34).

Ainda sob esse prisma, Stuart Hall (2013) analisa o conceito de "Raça", entendendo-a como um significante flutuante. Para ele, a cor é elemento concreto que pode produzir significações diversas. Ao citar Du Bois, Hall observa que "a cor, embora pouco significativa em si, é importante (...) 'como distintivo da herança social da escravidão, da disseminação e do insulto dessa experiência'”. 
Assim, desenha-se no âmbito teatral uma situação que se vai reproduzir posteriormente nas produções cinematográficas e televisivas, com a exclusão da presença do ator negro e a esteriotipia marcada em sua representação (muitas vezes feita por atores brancos pintados de preto), alinhando-se ao discurso histórico produzido pela historiografia oficial:

o português é o desbravador corajoso e aventureiro que vai criando o solo nacional (...) o índio é o símbolo audaz, guerreiro e puro, enquanto o negro simplesmente não aparece, substituído pela escravidão como instituição bárbara que é preciso destruir (CHAUI, 2007, p.51).

Nesse contexto, cabe o questionamento sobre as condições que permitiram a criação de uma Companhia Negra de Revistas no Brasil, no início do século XX. Nesse sentido, busca-se entender que discursos sustentaram seu estabelecimento no ambiente teatral carioca. Para tanto, é necessário que se entenda primeiramente de que maneira as criações discursivas do Projeto Civilizatório Brasileiro influenciaram o pensamento sobre as questões raciais no país. Não se pretende com isso, criar uma narrativa que sustente a total mudança de paradigmas ou que apresente discursos hegemônicos sobre o tema, mas, justamente, entender em quais debates a Companhia se insere, numa relação dialógica.

\section{ATO II: O PROJETO CIVILIZATÓRIO BRASILEIRO E A CRIAÇÃO DA IDENTIDADE NACIONAL}

O momento histórico proporcionador do surgimento da Companhia Negra de Revistas está intimamente ligado aos discursos produzidos pelo Projeto $\mathrm{Ci}$ vilizatório Brasileiro, iniciado no século XIX. Portanto, entende-se que o discurso fundador da história do país e da ideia de nação é reatualizado em diversos momentos históricos. Em outras palavras, os discursos nacionalistas se apropriam dos símbolos eleitos como "tipicamente nacionais", de diferentes formas ao longo do tempo, segundo os interesses das classes dominantes - o que não exclui, como veremos, a participação popular.

O momento-chave para o pontapé inicial dessa história, segundo Prado Junior (1945, apud SCHWARCZ, 2013, p. 4), "é sem dúvida a emancipação política de 1822. Nesse contexto, era preciso não só formalizar nossa separação da metrópole portuguesa como também tomar algumas medidas emergenciais, todas elas justificadas em termos de seu papel estratégico". Para tanto, foram criadas faculdades de medicina e de direito com vistas ao combate das mais variadas moléstias e à formalização da soberania nacional, dotada de leis próprias. Nesse senti- 
do, a ideia de nação, entendida como Estado-nação é "definida pela independência ou soberania política e pela unidade territorial e legal" (CHAUI, 2007, p. 12).

Seguindo essa lógica, a terceira instituição criada foi o Instituto Histórico e Geográfico Brasileiro (IHGB), responsável pela "invenção" de uma história para o país. Assim, poderíamos dizer que o IHGB ficou responsável por criar o que Marilena Chaui (2007, p. 12) chama de semióforo:

Um semióforo é um signo trazido à frente ou empunhado para indicar algo que significa outra coisa e cujo valor não é medido por sua materialidade e sim por sua força simbólica: uma simples pedra, se for o local onde um deus apareceu, ou um simples tecido de lã, se for o abrigo usado, um dia, por um herói, possuem um valor incalculável, não como pedra ou como pedaço de pano, mas como lugar sagrado ou relíquia heroica. Um semióforo é fecundo porque dele não cessam de brotar efeitos de significação (...) são capazes de relacionar o visível e o invisível, seja no espaço, seja no tempo (...) os semióforos religiosos são particulares a cada crença, os semióforos da riqueza são propriedade privada, mas o patrimônio histórico-geográfico e artístico é nacional.

A autora considera ainda que há um semióforo-matriz, elemento simbólico responsável por guardar os semióforos produzidos por ele. Esse semióforomatriz é a nação. "Por meio do patrimônio histórico e geográfico e dos monumentos aleatórios, o poder político faz da nação o sujeito produtor de semióforos nacionais e, ao mesmo tempo, o objeto do culto integrador da sociedade una e indivisa (CHAUI, 2007, p. 14).

Desse modo, podemos entender que o concurso promovido pelo Instituto Histórico e Geográfico por volta de 1844, intitulado Como escrever a história do Brasil, procurava instituir uma história para a constituição desta nação e a legitimação de sua existência. Nesse sentido, entende-se que a criação de uma história esteja intimamente ligada à criação de uma nação e que os dois conceitos sejam frequentemente ressignificados a partir das diversas simbolizações agregadas aos semióforos que as constituem.

A tese vencedora do concurso promovido pelo IHGB foi a do naturalista alemão Karl Von Martius, ficando a escrita da história do Brasil a cargo de um europeu que vai tratar não somente da "invenção do selvagem" como sugerem os escritos de De Certeau sobre as viagens de Jean de Lèry mas, principalmente, da invenção do brasileiro civilizado. Segundo Jurandir Malerba (2000, apud GONçALVES, 2008, p. 133),

a experiência histórica de um projeto civilizador brasileiro se deu a partir de um processo colonizador precedente (...) durante o pe- 
ríodo colonial, a cultura erudita legitima a sobreposição da cultura do continente metropolitano sobre a cultura local e insinua, assim, uma visão "de fora para dentro" em que o modelo de desenvolvimento brasileiro seria o de civilização europeia. Mesmo a partir da independência, quando a cultura erudita muda o tom e tende a exaltar o nativo, usando seus mitos e imagens para introjetar a noção de uma identidade nacional e uma ideologia conservadora, tanto o tipo ideal de comportamento individual quanto o modelo de nação a ser perseguido giram em função de mesmo projeto civilizador-progressista.

Portanto, "ainda que o poder político estivesse oficialmente em serviço pelos interesses locais, o ideal civilizatório figurou-se como um projeto interno que continuava em pauta sob o mesmo molde da moderna e progressista cultura ocidental europeia" (GONÇALVES, 2008, p. 132-133).

A partir disso, podemos considerar que o Projeto Civilizatório Brasileiro, ao mesmo tempo que buscou a valorização de alguns símbolos como representação de um caráter nacional, o fez sob uma perspectiva de exportação e dentro da lógica colonialista, a partir do olhar do estrangeiro sobre o outro exótico. Um dos exemplos máximos dessa lógica foi o discurso da mestiçagem como representativa da identidade nacional, já presente na tese de Von Martius (1991, apud SCHWARCZ, 2013, p. 4):

Devia ser um ponto capital para o historiador reflexivo mostrar como no desenvolvimento sucessivo do Brasil se acham estabelecidas as condições para o aperfeiçoamento das três raças humanas que nesse país são colocadas uma ao lado da outra, de uma maneira desconhecida na história antiga, e que devem servir-se mutuamente de meio e fim (...) O gênio da história (...) não poucas vezes lança mão de cruzar raças para alcançar os fins mais sublimes na ordem do mundo (...). Jamais nos será permitido duvidar que a vontade da providência predestinou ao Brasil esta mescla.

A tese monogenista, que considera derivarem todas as raças humanas de um tipo primitivo comum e une as ideias de nação e miscigenação como predestinação de um povo, foi adotada por inúmeros institutos históricos no Brasil, mas não aceita hegemonicamente. Nesse sentido, a miscigenação, apesar de entendida como característica nacional, foi repudiada como geradora de atraso civilizacional, visto que os elementos negro e indígena eram tidos como evolutivamente inferiores. Assim, de acordo com Lilia Schwarcz (2012, p. 3),

na verdade, raça, no Brasil, jamais foi um termo neutro; ao contrário, associou-se com frequência a uma imagem particular do país. 
Muitas vezes, na vertente mais negativa de finais do século XIX, a mestiçagem existente no país parecia atestar a falência da nação. Nina Rodrigues, por exemplo, um famoso médico da escola baiana, adepto do Darwinismo racial e dos modelos do poligenismo - que defendiam que as raças humanas correspondiam a realidades diversas e portanto não passíveis de cruzamento -, acreditava que a miscigenação extremada era ao mesmo tempo sinal e condição de degenerescência.

Por conseguinte, temos uma contradição acerca da associação da mestiçagem ao caráter nacional que, por um lado, não sugere uma valorização real do elemento mestiço, visto apenas como símbolo do exótico pelo olhar estrangeiro e gera um racismo velado a partir da ideia de que, no Brasil, ninguém é branco. Liv Sovik (2009, p. 39) considera que

o discurso da mestiçagem não significa que os setores dominantes se imaginam sempre como não brancos. A adoção do discurso da mestiçagem é uma antiga concessão, incorporada no decorrer dos anos pelo senso comum, à presença maciça de não brancos em uma sociedade que valoriza a branquitude.

Por outro lado, a negativização da mestiçagem a incorpora num discurso de branqueamento, que considera que, com o planejamento adequado, a partir da imigração do elemento branco, os resultados dos cruzamentos entre as raças acabarão por excluir o elemento negro do Brasil. João Batista Lacerda (1911, apud SCHWARCZ, 2012, p. 3) aredita que "é lógico supor que, na entrada do novo século, os mestiços terão desaparecido no Brasil, fato que coincidirá com a extinção paralela da raça negra entre nós".

A busca do branqueamento corresponde, em sentido geral, à busca da civilização baseada nos moldes europeus. Oliveira Vianna (1934, p. 285), em seus estudos racialistas, considerou o elemento negro primitivo e incapaz de criar civilizações:

Que os estudos do passado e as investigações dos archeologos assignalam a existência dos grandes centros de cultura nas regiões centraes da Africa, é o que não ponho em dúvida; mas, que estas civilizações sejam criações da raça negra é o que me parece contestável. Não sei si o negro é realmente inferior, si é igual ou mesmo superior as outras raças; mas julgando pelo que os testemunhos do presente e do passado demonstram, a conclusão a tirar é que, até agora, a civilização tem sido apanágio de outras raças que não a raça negra; e que, para que os negros possam exercer um papel civilizador qualquer, faz-se preciso que eles se caldeiem com outras 
raças, especialmente como as raças aryanas ou semitas. Isto é: que percam sua pureza.

As teorias de branqueamento também estão representadas em nossa iconografia. O quadro Redenção de Can (1985), do pintor espanhol Modesto Brocos y Gomèz, se mostra como um espelho dos discursos que consideram o branqueamento fator de salvação; incorporado aos ideais nacionais e incorporador deles.

A partir do final dos anos 20, porém, os modelos raciais de análise começam a passar por um crivo crítico, assim como já ocorrera em outros contextos intelectuais e momentos históricos, revalorizando positivamente a temática das "três raças", posteriormente endossada pela obra de Gilberto Freyre. Nesse momento, as correntes intelectuais ligadas ao poder público se dedicaram a pensar sobre políticas culturais que viabilizassem uma autêntica identidade brasileira a partir da cultura popular (SCHWARCZ, 2013). Alguns elementos se juntaram no processo de redefinição da autoimagem brasileira: o samba, a feijoada, a mulata, a malandragem, entre outros. Nesse contexto, é criada em meados de 1926, a Companhia Negra de Revistas.

\section{ATO III: BREVE HISTÓRICO DA COMPANHIA NEGRA DE REVISTAS}

As questões apresentadas até então, podem ser diretamente ligadas à trajetória da Companhia Negra de Revistas a partir de um olhar contemporâneo. No entanto, a fim de que não se tome a trajetória da Companhia à revelia do movimento teatral corrente na época, levando-se em consideração que algumas questões abordadas adiante prescindem de contextualização, propõe-se um breve histórico do chamado teatro ligeiro no Brasil e a inserção da Companhia Negra nesse panorama.

O Teatro Alcazar Lyrique, criado em 1859, é considerado o marco inaugurador do teatro ligeiro no Brasil. A expressão se refere aos duetos, vaudevilles, operetas, mágicas e ao teatro de revista, que tinham como característica comum o uso da dança, da música e das cenas cômicas, além da exacerbada sensualidade das figuras femininas. $O$ gênero cômico e musicado não tardaria em se tornar hegemônico nos palcos fluminenses, especialmente o teatro de revista, que se tornou uma das formas de entretenimento mais populares da capital federal (algumas companhias chegavam a apresentar três sessões de um espetáculo num só dia). Paralelamente, nesse mesmo período, a cena teatral vinha sendo assombrada por uma crise crescente de público e renda motivada pela consolidação da indústria cinematográfica no Brasil. Tal fato gerou a então chamada 
reação modernizadora, particularmente forte depois da Primeira Guerra Mundial, no Rio de Janeiro.

A reação modernizadora buscou incorporar aos espetáculos uma grande variedade de experimentos. Segundo Orlando de Barros (2005, p. 12),

agora, os exercícios infindáveis da coreografia, a importação do maquinário, o advento das cortinas de fumaça, as apoteoses deslumbrantes, a obrigatoriedade da iluminação sofisticada e os experimentos "modernos" e mesmo "futuristas" em matéria de cenários e figurinos convergiam para uma ampla operação de salvamento da revista.

Como parte do processo modernizador ocorrido na esfera do teatro de revista, houve a inserção de coristas negras nos espetáculos. No entanto, esse "advento" importado da Europa não significou, a princípio, uma mudança de paradigmas para se pensar o lugar do elemento negro nos palcos cariocas. Assim, a inserção das black girls foi apenas mais uma característica de excentricidade, não contribuindo para o estabelecimento de mais debates.

Foi nesse cenário que ocorreu a criação da Companhia Negra de Revistas em meados de 1926. A Troupe Chocolatina, como ficou conhecida posteriormente, foi formada por artistas negros e mulatos sob o comando do coreógrafo baiano De Chocolat e do cenógrafo português Jaime Silva. Com carreira estabelecida no Brasil e no exterior, De Chocolat era conhecido por seus múltiplos talentos, acumulando, ao longo de sua carreira, as funções de "cançonetista, improvisador, diseur e dançarino" (BARROS, 2005, p.53), tornando-se bastante famoso no meio teatral.

Em 1925, a propósito de sua estada na Europa juntamente com a companhia espanhola da qual fazia parte como cançonetista, De Chocolat assiste ao espetáculo francês Revue Nègre, que tinha como protagonista a atriz negra americana Josephine Baker. Ao retornar para o Brasil, ele decide criar sua própria Companhia Negra de Revistas. A resolução, quer se tenha baseado em interesses comerciais, quer se tenha baseado na proposta ideológica de valorização do artista negro, dialogou diretamente com as produções discursivas do Projeto Civilizatório Brasileiro (historicamente recente) a propósito de sua atualização na década de 20.

\section{ATO IV: A COMPANHIA NEGRA DE REVISTAS NOS ATRAVESSAMENTOS DO DISCURSO CIVILIZADOR}

O movimento de atualização da mestiçagem como característica positiva de identidade nacional, já citado, favorece, a princípio, o aparecimento da Com- 
panhia Negra em 1926. Aliada a isso, a apresentação da Revue Nègre francesa autoriza e legitima o empreendimento brasileiro sob o ponto de vista da lógica civilizatória, agregadora do pensamento colonialista e reveladora da busca da modernidade representada pela cultura europeia. Com base nessa lógica, o "retorno" do elemento negro aos palcos cariocas é embasado por um movimento "de fora para dentro". Nesse sentido, Orlando de Barros (2005, p. 14) compreende que a companhia negra não deixou de ser um reflexo brasileiro de um movimento internacional de valorização da cultura negra sincrética, que já havia conquistado espaço desde a segunda metade do século XIX, acelerando-se particularmente depois da Primeira Grande Guerra, com o irrompimento do jazz e dos diversos gêneros de dança que ganharam o mundo.

A partir disso, não se pretende afirmar que a Companhia Negra de Revistas foi aceita hegemonicamente no meio teatral, inaugurando uma nova era para o ator negro brasileiro, que passou a ser integrado nas atividades teatrais sem ressalva; o momento teatral posterior ao fim da Companhia e a criação do Teatro Experimental do Negro em 1944 são exemplos de que essa afirmação não poderia ser verdadeira. Da mesma forma, não se pretende concluir que a criação da Companhia ocorreu por conta de um momento histórico propiciador, sem mais debates. Pretende-se apenas ressaltar que a criação da Companhia Negra está diretamente ligada a um contexto com o qual dialoga; além disso, pretende-se aprofundar o discurso corrente que tende a "ressaltar alguns comentários preconceituosos da imprensa da época, indicando que a companhia teria triunfado brilhantemente apenas devido a seu mérito, vencendo os preconceitos de toda uma sociedade" (GOMES, 2001, p. 61).

Assim, entende-se a trajetória da Companhia dentro de um cenário mais complexo, no qual a mestiçagem se apresenta na duplicidade das correntes racialistas do século anterior, a partir dos discursos correntes no jornalismo fluminense. Por um lado, partindo das teorias poligenistas aliadas a posteriores discursos racistas, o negro, considerado em seu primitivismo, é entendido como incapaz da realização de um empreendimento artístico. Essa lógica se coaduna perfeitamente às perspectivas racistas geradas pelo alinhamento entre as figuras do negro e do escravo, nesse caso, a da empregada doméstica, já citadas no corpus deste artigo:

Anuncia-se para estes dias a estreia de uma companhia de revistas, cujo elenco é formado unicamente por "artistas negros" e até mesmo a peça de estreia é escura, chama-se: "Tudo Preto"... A originalidade e novidade entre nós da tal companhia está despertando grande interesse no público, mas temos certeza de que se já me- 
ditou a respeito, uma certa classe, deve estar bastante apreensiva com esta ideia de companhia "escura" de revistas...e essa classe é a das donas de casa, das patroas que têm que lidar com a criadagem e resolver constantemente o sério problema de arranjar criadas, que pousem um pouco em suas casas. $O$ aumento constante do número de sociedades-dançantes nos bairros e ainda das reuniões semanais, hoje às quintas, sábados e domingos, constitui agora um tormento para as donas de casa. Agora, a tal Companhia Negra de Revistas é muito capaz de vir complicar ainda mais o problema da criadagem. Cozinheiras e arrumadeiras há hoje que são exímias na arte coreográfica. Essas talvez sintam-se tentadas agora a exibirem a sua arte no palco, outras como simples comparsas, abandonando os seus empregos atuais ou sacrificando-os como melhor puderem... Assim, pode desde já a Companhia Negra estar certa de que ninguém mais do que as patroas "torcem" para o seu insucesso e vida curta (1926 apud BARROS, 2005, p. 129).

Por outro lado, a mestiçagem como característica positiva, perpassada pelo olhar eurocêntrico colonizador também se manifesta no discurso da imprensa (1926, apud BARROS, 2005, p. 46) dos anos 20, a propósito da criação da Companhia Negra:

O negrismo é a grande moda do momento. Paris delirou longos meses, diante de uma companhia negra de revistas. E Josephine Baker, negra autêntica, é hoje uma das popularidades mais fascinantes do "boulevard" parisiense. Agora, Londres também quis ver uma companhia negra. E mandou buscá-la em Paris. Foi a Cidadeluz que organizou, para enviar a Londres, o Bataclan Negro. Essa curiosa "troupe" vai à Inglaterra representar a revista "Pessoas Negras" que fez grande sucesso em Paris. É uma companhia de pretos autênticos. Mas nós, que cá temos "De Chocolat" e a sua tribo, não devemos ter inveja de Paris nem de Londres... Negros por negros, nós cá também os temos - e dos melhores.

O tema da mestiçagem, na trajetória da Companhia Negra manifestou-se para além das estruturas discursivas presentes nas reportagens e críticas. É importante considerar que a Companhia participou dos debates sobre identidade nacional vigentes na época através de personagens, canções e textos constituintes do olhar sobre sua própria negritude. De acordo com Tiago de Melo Gomes (2001, p.57),

mestiçagem, influências negras na cultura brasileira, racismo, influências regionais diferenciadas em um caráter nacional único, todas questões caras a intelectuais como Gilberto Freyre, eram debatidas 
por uma companhia negra de teatro perante um público tão amplo quanto internamente diferenciado, seja em termos étnicos, como nos aspectos socioeconômicos.

Nesse sentido, reivindica-se um espaço mais amplo aos debates sobre a identidade nacional ocorridos nos anos 20 e 30. Assim,

o que se pretende aqui não é negar a possibilidade de que alguns intelectuais, políticos e membros da elite possam ter desempenhado papel destacado na definição da identidade nacional; seria desejável, antes, apontar o fato de que os debates promovidos nestes círculos não estavam isolados de discussões semelhantes que ocorriam em âmbito mais amplo (GOMES, 2001, p. 59).

Com isso, não se pretende afirmar que todos os espectadores do teatro de revista tenham voltado para casa convencidos de que malandros, mulatas, portugueses e caipiras serviriam como personificação do país, visto que, segundo Michel De Certeau (1998, apud GOMES, 2001, p. 61), "a produção cultural de massas é necessariamente reinterpretada pelos consumidores". Assim, "a concordância sobre o caráter 'mestiço' da nação poderia gerar simpatia, revolta ou mero divertimento para o público do teatro de revista (...) Mas não se pode negar a presença deste debate em um nível mais amplo que o tradicionalmente apontado pela bibliografia" (GOMES, 2001, p. 61).

Faz-se importante acrescentar que, em sua meteórica trajetória (19261927), a Companhia Negra de Revistas produziu três espetáculos, todos eles fazendo menção à cor da pele: Tudo Preto, Preto e Branco e Café Torrado. A primeira e mais popular produção ficou pouco mais de um mês em cartaz, posteriormente excursionando por algumas cidades do Brasil. Tiago de Melo Gomes (2001, p. 67) afirma que a recepção positiva da primeira peça da companhia pode indicar que "um tipo de caracterização dos negros fosse algo muitas vezes encarado de forma positiva no ambiente do entretenimento massificado do Rio de Janeiro dos anos 1920". Sendo assim, a atualização do discurso da mestiçagem e sua ampliação para fora da esfera intelectual podem ser reconhecidos na fala de um dos personagens de Tudo Preto: "o preto é quem está na moda. O próprio branco brasileiro, despido de preconceitos, reconhece isto e nos adora" (p. 68), além de se manifestar nos usos de personagens e elementos icônicos como a mulata, o malandro e a feijoada.

Os próprios homens negros de "verdadeiro valor", que são citados na peça, ajudam a confirmar esta concepção: "Henrique Dias, Cruz e Sousa, André Rebouças, José do Patrocínio, Luís Gama, entre outros". Basta lembrar que, nos cânones da história oficial, Henrique Dias foi o negro que, junto com o índio Filipe Camarão e o branco 
André Vidal de Negreiros, teria liderado a expulsão dos holandeses de Pernambuco em 1654, em um episódio recorrente para exaltar a ideia das três raças fundadoras de uma nacionalidade mestiça (GOMES, 2001, p. 68).

Dessa forma, percebe-se de que maneira os discursos civilizatórios atravessam a trajetória e as produções da Companhia Negra de Revistas e são por ela atravessados. Com isso não se pretende lançar um julgamento de valor sobre o trabalho da Companhia, desvalorizando-o; busca-se apenas entendê-la num contexto específico em que "as ideias sobre um 'Brasil Mestiço', hoje tidas como mascaradoras do racismo brasileiro, tinham, em outro contexto histórico, sido populares entre os negros, inclusive os que militavam abertamente contra o racismo" (GOMES, 2001, p.70).

Outro ponto importante, muitas vezes desprezado pela bibliografia corrente, diz respeito aos ecos que o discurso civilizatório, através da busca de modernidade, produziu na dissolução da Companhia Negra de Revistas, em 1927. O fato se deu a propósito da possível viagem da Troupe Chocolatina para apresentações em Buenos Aires e no Uruguai, a convite de uma empresa argentina. Após tomar ciência do fato, a Sociedade Brasileira de Autores (SBAT) (1927, apud BARROS, 2005, p. 230) se pronunciou contra a viagem da Companhia, "o que redundará em descrédito do nosso país, a SBAT, como lhe cumpre, irá agir energicamente a fim de impedir a consumação desse atentado aos foros da nossa civilização".

Apesar da valorização, já aludida, da cultura negra em âmbito mundial e do crescente interesse argentino pelo negro brasileiro, Orlando de Barros (2005, p. 238) aponta que as teorias de branqueamento atualizadas nos discursos de alguns setores da imprensa, por ocasiões específicas, faziam

reviver as inevitáveis comparações entre os graus de civilização das duas nações, quase sempre atribuídos retrogradamente aos componentes étnicos das duas populações nacionais (...) É neste ponto que se inscreve o prioritário projeto de reforma urbana da capital federal no começo do século XX, concomitante com o plano da higienização compulsória e radical, medidas tidas como indispensáveis para redimir o conceito do Brasil no estrangeiro, e argumento de que tais políticas incluiriam o país no rol do progresso da civilização ocidental.

Desse modo, a sugestão de que negros brasileiros se apresentassem em Buenos Aires foi vista com desconforto no Brasil. Assim, proibida de se apresentar no exterior, também abalada por dissonâncias internas, dissolve-se em 1927 a Companhia Negra de Revistas. 


\section{APOTEOSE}

Este artigo, partindo de um recorte histórico-cultural, traçou um breve panorama das artes cênicas no Brasil, especialmente no Rio de Janeiro, a fim de entender de que forma o artista negro esteve inscrito nos palcos brasileiros tanto como intérprete quanto como personagem. Tal trajetória foi entendida como possível reveladora das relações raciais existentes na presença/ausência do elemento negro na cena.

Da mesma forma, contextualizou o momento de criação do Projeto Civilizatório Brasileiro, assim como o entendeu em sua estrutura discursiva, a fim de percebê-lo como fundador de enunciados, às vezes contraditórios, na construção da imagem do Brasil enquanto nação nas suas demandas de história e identidade.

Por fim, dedicou-se a relacionar a trajetória da Companhia Negra de Revistas em suas criação, produções e dissolução ao contexto histórico a que pertencia e aos atravessamentos sofridos pelas atualizações das estruturas discursivas do Projeto Civilizatório, principalmente no que diz respeito ao uso da mestiçagem como característica nacional, em seus aspectos contraditórios. Assim, não pretendeu esgotar as questões sobre o tema proposto, mas sim lançar o olhar sobre questões pertinentes aos estudos sobre representações da africanidade, a partir de uma companhia negra brasileira, no campo das artes cênicas.

CAI O PANO

\section{REFERÊNCIAS BIBLIOGRÁFICAS}

BARROS, Orlando. Corações De Chocolat: a história da Companhia Negra de Revistas (1926-1927). 1 ed. Rio de Janeiro: Livre Expressão, 2005.

CHAUI, Marilena. Brasil: mito fundador e sociedade autoritária. São Paulo: Editora Fundação Perseu Abramo, 2007.

GOMES, Tiago de Melo. Negros contando (e fazendo) sua história: alguns significados da trajetória da Companhia Negra de Revistas (1926-1927). Estudos Afro-asiáticos, Rio de Janeiro, ano 23, n. 1, 2001, p. 53-83.

GONÇALVES, Sergio Campos. O pensamento civilizador e a cultura historiográfica brasileira no século XIX. Revista Fazendo História, on-line. Rio Grande do Norte, ano I, edição 02, 2008. Disponível em http://www.cchla.ufrn.br/fazendohistoria/downloads/revista/edicao2/Fazendo_Historia_Edicao2_Completo.pdf. Acesso em 30 nov 2014.

HALL, Stuart. Raça, o significante flutuante. Revista Z Cultural, on-line. Rio de Janeiro, v. 2, n. 2, 2013. Disponível em: revistazcultural.pacc.ufrj.br/raca-o-significante-flutuante\%EF\%80\%AA/. Acesso em 30 nov 2014.

MARTINS, Leda Maria. A cena em sombras. São Paulo: Editora Perspectiva, 1995. 
MENDES, Miriam. A personagem negra no teatro brasileiro entre 1838 e 1888. São Paulo: Ática, 1982.

PRADO, Décio de Almeida. As raízes do teatro brasileiro. In FARIA, J.B. (Dir.). História do teatro brasileiro. São Paulo: Editora Perspectiva, 2012, p. 21-66.

SCHWARCZ, Lilia. Complexo de Zé Carioca: notas sobre uma identidade mestiça e malandra. 2013. Disponível em: http://www.anpocs.org.br/portal/publicacoes/rbcs_00_29/rbcs29_03.htm. Acesso em 30 nov. 2014. . Nem preto nem branco, muito pelo contrário: cor e raça na intimidade. In História da vida privada. São Paulo: Companhia das Letras, 2012.

SOVIK, Liv. Aqui ninguém é branco. Rio de Janeiro: Aeroplano Editora, 2009.

VIANNA, José de Oliveira. Raça e assimilação. São Paulo: Companhia Editora Nacional, 1934.

Daniele Lopes dos Santos é mestranda em artes cênicas pela Universidade Federal do Estado do Rio de Janeiro - UNIRIO. Possui graduação em artes cênicas com habilitação em direção teatral pela Universidade Federal do Rio de Janeiro - UFRJ (2008) e especialização em arte, cultura e sociedade no Brasil pela Universidade Veiga de Almeida (2013). Atua como professora tutora na Universidade de Brasília - UNB e no Instituto Arte na Escola.

Recebido em: 16/04/2015

Aceito em: 30/04/2015 